\title{
Cartas Cirandeiras: Relatos de professores em tempos de pandemia
}

\author{
Ciradeiras Letters: Teachers' reports in times of \\ pandemic
}

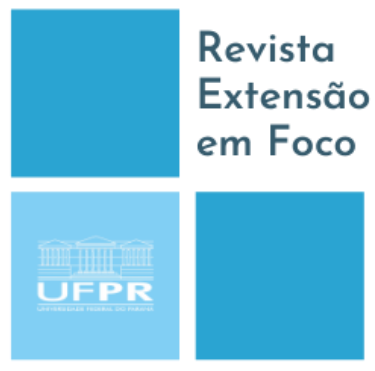

ISSN 2358.7180

Mara Elisângela Jappe Goi ${ }^{1}$

\begin{abstract}
RESUMO
Neste texto, apresento um relato de participação no processo formativo cirandar promovido pela Universidade Federal do Rio Grande (FURG). Em 2018, o Cirandar foi ampliado a outras instituições que teriam polos de organização das atividades formativas e em 2020 o cirandar abrangeu 9 polos. Aqui, relato com foi encaminhado o processo em 2020 no polo da Universidade Federal do Pampa, Unipampa, campus, Caçapava do Sul, RS. O grupo foi constituído por 18 integrantes, sendo da rede Básica de Ensino, da Educação Superior, discentes de Programa de pós-graduação e graduação. O processo de escrita em cartas e reflexões fomentado pelo Cirandar aconteceu durante os meses de setembro de 2020 a março de 2021, para isso foram organizados encontros remotos via Goole Meet. A Carta I traz uma breve apresentação do cirandeiro, a carta II revela o que cada cirandeiro pretendia escrever e a Carta III foi retomada com o estudo daquilo que cada cirandeiro se propôs a escrever na Carta II. Neste trabalho apresento os relatos de professores que participaram do cirandar 2020 sobre tempos de pandemia. Para a produção de dados da escrita da carta III foi aplicado um questionário via google drive. Estes dados foram analisados de forma qualitativa. Como resultado percebo que os professores apontam dificuldades vivenciadas neste momento, como a falta do convívio social e o receio em enfrentar este novo normal. Também apresentam pontos positivos, como ter mais tempo para fazer cursos de formação continuada e estar mais tempo junto à família.
\end{abstract}

Palavras-chave: Pandemia. Perspectivas pós-pandemia. Formação de professores.

\section{ABSTRACT}

In this text, I present an account of participation in the Cirandar training process promoted by the Federal University of Rio Grande (FURG). In 2018, Cirandar was extended to other institutions that would have centers for organizing training activities and in 2020, Cirandar covered 9 centers. Here, I report how the process was conducted in 2020 at the pole of the Federal University of Pampa, Unipampa, campus, Caçapava do Sul, RS The group consisted of 18 members, being from the Basic Education network, from Higher Education, students from the graduate and undergraduate. The process of writing letters and reflections fostered by Cirandar took place during the months of September 2020 to March 2021, for which remote meetings were organized via Goole Meet. Letter I provides a brief presentation of the surgeon, letter II reveals what each surgeon intended to write and Letter III was taken up with the study of what each surgeon proposed to write in Letter II. In this paper I present the reports of teachers who participated in the 2020 cirandar about pandemic times. For the production of data from the writing of letter III, a questionnaire was applied via google drive. These data were analyzed qualitatively. As a result, I realize that teachers point out difficulties experienced at this moment, such as the lack of social

1 Doutora em Educação, Docente da Universidade Federal do Pampa (Unipampa), Caçapava do Sul, RS, Brasil. E-mail: maragoi28@gmail.com Orcid: https://orcid.org/0000-0002-4164-4449 
life and the fear of facing this new normal. They also have positive points, such as having more time to take continuing education courses and being more time with the family.

Keywords: Pandemic. Post-pandemic perspectives. Teacher training.

\section{INTRODUÇÃO}

\section{CARTA 1-Apresentação ao Encontro Cirandar}

Canoas, 17 de setembro de 2020.

Começo esta escrita refletindo sobre o momento que estamos passando. A meu ver parece que 2020 ainda não iniciou, mas ao mesmo tempo estou com muitas tarefas a fazer, pois são muitas demandas do trabalho docente.

Com este desabafo inicial começo esta carta relembrando da minha trajetória em eventos presenciais de Ensino e Educação que ao longo desses 27 anos de magistério venho participando e contribuindo com a área, principalmente em temáticas que envolvem a formação de professores. Hoje estes encontros vêm acontecendo de forma remota através do uso de plataformas digitais.

Desde minha graduação, no início dos anos 90 participo de eventos presenciais que a cada encontro me fortalecem. Entre um encontro e outro, uma história e outra, uma palestra e outra me constituo como pessoa e profissional.

Foram muitos EDEQs, ENEQs, ENPECs, Investigações na Escola, Cirandar, etc. É muito bom chegar nos eventos e rever amigos e colegas de profissão. Discutir temáticas pertinentes à nossa constituição profissional e pessoal. É isso que espero desse cirandar, que possamos construir um grupo fortalecido com a nossa prática docente e a nossa vivência pessoal, mesmo que nossos encontros acontecerão de forma remota. Afinal, o remoto é o desafio para o professor no ano de 2020.

Contar em cartas o nosso "EU" profissional, para que no final possamos através de um relato escrever a nossa vivência da escola, da universidade, espaços esses que muitas vezes o professor se sente sozinho.

Desejo ao grupo cirandar e em especial aos Cirandeiros da Unipampa de Caçapava do Sul um ótimo evento e que possamos ao longo destes próximos meses fazer boas reflexões, leituras e escritas. 
Abraços Cirandeiros:

Mara E. Jappe Goi

CARTA 2- O que estudar em tempos de pandemia?

Canoas, 27 de outubro de 2020.

Estimados cirandeiros,

Estou escrevendo para comunicar que pretendo realizar o meu relato do Encontro Cirandar sobre alguns tópicos que venho percebendo ao ouvir cada professor nos encontros de formação continuada. São muitas as angústias que os professores vêm comentando durante os momentos formativos, algumas se referem aos processos de ensino e de aprendizagem que estão sendo realizados de forma remota; outros acenam sobre os processos de aprendizagem, comentando sobre a ineficiência do ensino remoto e alguns comentam sobre sua sobrecarga de trabalho.

Também estou intrigada em pesquisar sobre os tipos de plataformas digitais que estão sendo usadas na modalidade de ensino remoto, sobre as suas dificuldades e potencialidades. Essas e outras questões permeiam o discurso docente. Poderia pesquisar e analisar as mais diversas questões, mas após me deparar com muitas incertezas dos professores estou convencida em pesquisar as angústias que os participantes do cirandar 2020 estão enfrentando neste momento de pandemia.

Abraços Cirandeiros:

Mara E. Jappe Goi

\section{CARTA 3- Relatos de professores em tempo de Pandemia}

A terceira carta está escrita em formato de relato, registrando concepções que os professores estão vivenciando neste momento de pandemia. As reflexões foram feitas durante os meses de setembro de 2020 a janeiro de 2021.

Início este relato refletindo sobre o momento de pandemia vivenciado há mais de 10 meses no Brasil. Em 26 de fevereiro de 2020 o Brasil teve a confirmação de seu primeiro caso de coronavírus. Coronavírus é uma família de vírus que causa infecções respiratórias, pertencente a um grupo de vírus de genoma de RNA simples de sentido positivo. É um coronavírus humano do gênero Betacoronavírus da espécie SARS-CoV 
subdividida na cepa SARSCoV-2 que em inglês significa Severe Acute Respiratory Syndrome Corona Virus 2 (WANG et al., 2020).

Os primeiros infectados pelo SARS-CoV-2 foram os chineses na cidade de Wuhan. Esta doença foi detectada pelas autoridades poucas semanas após ter se espalhado entre a população humana no fim do ano de 2019 e na primeira quinzena de janeiro de 2020 já havia disseminado entre seres humanos (WANG et al., 2020).

No dia três de fevereiro de 2020, o Ministério da Saúde declarou Emergência de Saúde Pública de Importância Nacional (ESPIN), por meio da Portaria MS n 188/20 e conforme Decreto ${ }^{\circ}$ 7.616, de 17 de novembro de 2011. (BRASIL, 2020). Nesta época acreditava-se que esse vírus poderia atravessar barreiras entre espécies e causar, em humanos, doenças que variam do resfriado comum a doenças mais graves (CUI et al., 2019). Hoje o que é presenciado são milhões de pessoas infectadas e mortas, bem como a variação do coronavírus na China, Canadá, Estados Unidos, Portugal, França Jordânia, Coreia do Sul e Chile, propagando para o restante do mundo. No Brasil, por exemplo, em 04 de janeiro de 2021 já se tem confirmado 2 pessoas em São Paulo como o novo coronavírus da variante inglesa. "De acordo com estudos apresentados no Reino Unido, a nova variação é de 50 a $74 \%$ mais contagiosa, mas não se sabe se a cepa é mais ou menos letal do que as já conhecidas [...]” (CORREIO BRAZILIENSE, 2021, p.1)

Há vários sintomas ocasionados pelo coronavírus, como tremores e calafrios, dores musculares, de cabeça e garganta, perda recente de olfato ou paladar, febre, dificuldade para respirar, tosse e diarreia. Assim, a Organização Mundial de Saúde (OMS) decreta pandemia com uma propagação mundial de uma nova doença. Isso ocorre quando um grande surto que afeta uma região se espalha por diferentes continentes com disseminação de pessoa para pessoa (FIORI; GOI, 2020).

Com a propagação do Coronavírus o Ministério da Saúde determinou a quarentena com distanciamento social. Com esta determinação vieram os fechamentos de escolas e comércio, o cancelamento de eventos, de trabalho em escritórios e de outras atividades que envolvem aglomerações de pessoas. Isso repercutiu por vários meses do ano de 2020 e ainda assola o mundo neste ano de 2021. Também se presenciou o isolamento de pessoas com mais de 60 anos, suscetíveis a doenças. Percebe-se que muitas ações foram adotadas, como lavar as mãos, com frequência, usando sabonete e água (por ao menos 20 segundos); utilizar como alternativo álcool 70\%; cobrir com lenço de papel 
boca e nariz ao espirrar ou tossir (e depois descartar o lenço); utilizar máscara; limpar objetos e superfícies tocados com frequência (maçaneta, telefone celular, controle remoto); evitar contato com pessoas doentes (afastamento) e ficar em casa, se estiver apresentando sintomas, mesmo que de gripe comum (BRASIL, 2020).

Foram várias ações utilizadas durante o ano de 2020 e perpassam este início de ano de 2021, porém, no final deste mesmo ano (2020), percebeu-se que que durante as festividades, no Brasil, ainda há a cultura da aglomeração. Várias cidades litorâneas demonstradas através dos meios de comunicações vislumbram praias lotadas, indo na contramão do isolamento social.

Por outro lado, em vários lugares do mundo iniciou-se no mês de dezembro de 2020 a vacinação para tentar sanar esta pandemia, porém, no Brasil, ainda não se tem um calendário de vacinas confirmado. Espera-se que durante os meses de janeiro e fevereiro do presente ano (2021), o governo federal, juntamente com a Agência Nacional de Vigilância Sanitária (ANVISA), proponha um calendário de vacinação. Estima-se que hoje, dia 06 de janeiro de 2021, no Brasil chegou-se há 197.732 mortes ocasionados pelo Coronavírus.

Diante deste quadro apresentado, percebo que há muitas angústias vivenciadas pelas pessoas durante este período de pandemia. Os professores, por exemplo, frequentemente, vêm comentando algumas destas angústias e muitas se referem aos processos de ensino e de aprendizagem; outros se referem à aprendizagem, comentando sobre a ineficiência do ensino remoto e, alguns discorrem sobre sua sobrecarga de trabalho e até mesmo as suas angústias pessoais. Essas e outras questões permeiam o discurso docente. Assim, o relato aqui apresentado tem por objetivo descrever as angústias que os professores estão passando neste período pandêmico.

\section{Contexto da experiência}

Durante o ano de 2020 realizou-se uma série de eventos no formato on-line. Para isso foram utilizadas plataformas digitais e o Cirandar de 2020 aconteceu desta forma. Para a organização deste evento foram realizadas reuniões mensais com os coordenadores de diferentes escolas e universidades dos Estados brasileiros. Além das reuniões com os coordenadores do evento foram realizados encontros mensais com as pessoas inscritas no evento, utilizando a plataforma Google Meet. Os sujeitos participantes deste evento são professores da rede básica de ensino, professores de Educação Superior e licenciandos. 
Estes encontros têm por objetivo relatar e refletir sobre as produções realizadas durante o Evento Cirandar 2020. Estas produções foram compostas através de cartas, em um total de três elaboradas pelos cirandeiros.

Para a produção de dados deste relato, foi organizado um questionário no google drive com questões referentes ao momento pandêmico. Optei por enviar os questionários aos 210 cirandeiros de 2020 e retornaram 28 respostas. Os sujeitos que responderam o questionário são na maioria professores da Educação Básica e da Educação Superior e alguns alunos da formação inicial, 89,3\% são mulheres e 10,7\% são homens, suas idades variam de 20 a 63 anos. Para resguardar a identidade dos sujeitos da pesquisa esses estão denominados pela letra $\mathrm{P}$, seguida da sequência numérica de 1 a 28.

No quadro abaixo descrevo as questões que compõem o questionário enviado aos Cirandeiros de 2020.

Quadro 1: Questionário sobre "tempo de pandemia"

\begin{tabular}{|ll|}
\hline 1- & Idade: \\
$2-$ & Sexo: ( ) Feminino $\quad($ ) masculino \\
$3-$ & Área de Atuação: \\
$4-$ & Estado/Cidade \\
$5-$ & Quais as angústias pessoais que vem passando neste período de pandemia? \\
$6-\quad$ & Quais as angústias profissionais que vem passando neste período de pandemia? \\
7- & Na sua opinião, como será o momento pós-pandemia? \\
\hline
\end{tabular}

Fonte: A autora

O questionário foi analisado de foram qualitativa e emergiram 2 categorias de análise, a saber: Angústias vivenciadas no período da pandemia e perspectivas do momento pós-pandemia.

A análise qualitativa busca fazer uma exposição e explicação dos dados produzidos (MINAYO; SANCHES, 1993). A seguir relato as categorias que emergiram a partir do questionário analisado.

\section{(1) Angústias vivenciadas no período da pandemia}


O momento de pandemia refletiu consideravelmente no setor da educação. Os professores tiveram que adaptar suas residências e suas metodologias de ensino, utilizando o modelo de ensino remoto, isso devido ao isolamento social.

Durante os meses de abril a dezembro de 2020 vivenciou-se uma realidade escolar diferente daquela que os professores e estudantes estavam habituados, ou seja, as aulas foram implementadas através do uso de plataformas digitais ou através de atividades enviadas semanalmente pelos professores, utilizando xerox ou imagens via WhatsApp.

O uso da plataforma digital em um momento de pandemia, não pode ser considerado como salvacionista, pelo contrário, ela está organizada devido a uma situação emergencial e se baseia na realização de atividades pedagógicas de forma temporária com o uso da internet (FIORI, GOI, 2020). Assim, as aulas ocorrem em um tempo síncrono (seguindo os princípios do ensino presencial) e assíncrono (atividades realizadas de forma não síncrona). Para que esta modalidade fosse implementada os professores tiveram que adaptar-se e estudar este novo formato de ensino, bem como, superar as suas limitações para implementar um ensino remoto de qualidade. A seguir relato nos excertos das falas dos professora P27, P18, P22 algumas das suas angústias vivenciadas durante o ano de 2020, na qual tiveram que adaptar-se a esta metodologia de ensino.

São muitas as angústias, começando pela forma inesperada que tivemos que nos adaptar sem tempo, preparo e nem orientação. A carga de trabalho é maçante porque são muitas horas na frente do computador, muita burocracia e praticamente nenhuma ajuda, é como se nada flui-se como gostaria. Eu, em particular, e sei que muitos colegas não dominam muitas ferramentas de tecnologia e desta maneira as tarefas são ainda mais complicadas e demandam muito tempo e dedicação pessoal. O mais decepcionante é tentar fazer o melhor possível e sentir que a maioria dos alunos não estão nem um pouco interessados e que não contamos com a ajuda da maior parte dos pais e, para completar, ainda tem o problema que apesar de "as notícias" informarem que a maioria das pessoas tem acesso à informação e os meios tecnológicos, hoje vivenciamos um momento que desmente essa informação e portanto o discurso de que após a pandemia usaremos muito mais as ferramentas tecnológicas se mostra uma inverdade, pois para isso primeiro é preciso realmente ter os recursos necessários para que isso ocorra e essa realidade ainda não contempla grande parte dos alunos e nem das escolas públicas. Ainda tem outro agravante que são as lives, não aquelas que escolhemos participar, mas as que muitas vezes somos obrigados a assistir em função de formação, novo ensino médio e os mais diversos temas como se já não tivéssemos tarefas suficientes para nos preocuparmos. Quando organizo o tempo para planejar aulas, fazer slides, escolher vídeo aulas, atividades práticas, em muitos momentos me questionam pra quem estou fazendo isso e por vezes fico sem resposta. Quando vejo postagem de fotos como seminários e meet onde é possível enxergar dois, três alunos e seis, sete 
professores também pergunto "Qual o sentido?"," Quantos participaram?" e pior que isso o quanto foi significativo e quantos alunos conseguiram adquirir pelo menos um pouquinho de conhecimento, e mais uma vez fico sem resposta. Sei que precisamos seguir em frente, mas o que não sei é se estamos trabalhando em prol de todos os alunos ou de um pequeno grupo e sendo de certa forma coagidos a dar notas, não reprovar, dizer que as tarefas estão sendo realizadas. Algo é certo em meio a incerteza, este será um ano em que os governantes anunciarão como o melhor índice de aprovação, já que ensino e aprendizagem nunca foram prioridade. (P27)

A falta de participação dos alunos nas aulas e como ficará essa defasagem (P18)

Várias, principalmente no que diz respeito aos alunos que não estão participando por vários motivos. estamos também angustiados com o próximo ano, com os próximos acontecimentos, como estarão esses alunos? como será o funcionamento das escolas? (p22)

Os excertos acima trazem o desabafo dos professore sobre o seu momento de planejamento e as incertezas sobre a eficiência ou ineficiência e abrangência do ensino remoto. Revela o quanto a educação não é prioridade nas famílias e tampouco dos governantes, pois a adesão ao ensino remoto é pequena, de uma turma com mais de trinta alunos, dois ou três participam. Revela-se nestas falas o quanto a família pode ser atuante e demostrar que a educação é prioridade.

Além da falta de adesão às aulas remotas, alguns professores revelam o acúmulo de atividades realizadas pelo corpo docente, os problemas de conexões enfrentados pelos alunos e professores, a falta de concentração, fruto do excesso de atividades, como relatam os professores P13 e P15. Este aspecto também é apontado por de Souza et al. (2020. p.3) quando revela que [...] Fazer do próprio ambiente doméstico o local de trabalho, em tempo integral, trouxe consequências pouco exploradas para a saúde dos profissionais da educação que sustentam, por longa data, esse híbrido entre compromissos contratuais e afazeres da vida privada.

Sentimento de estar faltando algo, de precisar dar conta de algo (penso que tem a ver com a imagem de que professor/funcionário público não trabalha). Dessa forma levando ao acúmulo de atividades profissionais e das novas demandas como conhecer os recursos tecnológicos e aprender a utilizá-los, pois precisamos ter condições de atender nossos estudantes da melhor forma possível. Também se torna angustiante) acompanhar os problemas de conexão durante as aulas (P13).

Dificuldade de concentração e de separar estudos com as atividades de casa. Excesso de coisas para fazer e todas no computador, acaba cansando a cabeça (P15).

A falta de participação dos alunos nas aulas e como ficará essa defasagem (P18). 
Outro aspecto relacionado a este novo fluxo de ensino está relacionado ao controle sobre o trabalho docente, como já apontado por alguns professores (P13, P15...). O trabalho docente passou a ser medido pelo [..] número de atividades pedagógicas realizadas pelos alunos no interior das plataformas e pela quantidade de avaliações da aprendizagem aplicada" (DE SOUZA, et al., 2020, p. 6). Isso leva a um desgaste físico e emocional, pois o professor acaba se preocupando com a quantidade e não com a qualidade, pois será cobrado pelo número de atividades postadas. Como afirmam estes autores:

\begin{abstract}
Esse controle sobre o processo de trabalho de professoras e professores, que inclui monitoramento das aulas on-line, por parte da coordenação pedagógica escolar, e 'visitas' às aulas virtuais em tempo real pela gestão da escola, sem acordo prévio com os docentes, suscita constrangimento e incômodo no ambiente de ensino. Por certo, novas exigências e modalidades de controle de gestão passaram a fazer parte da rotina do trabalho docente, de modo que as metas escolares a serem alcançadas expressam o aumento da produtividade sob parâmetros quantitativos[...]. (DE SOUZA et al., 2020, p. 7).
\end{abstract}

Os professores além de relatar sobre suas angústias profissionais também revelam as suas angústias pessoais, principalmente aquelas relacionadas a sua saúde física e mental, bem como, a saúde de seus familiares. A Solidão, o medo, a falta de estar com os familiares, o isolamento social, a angústia devido à falta de estabilidade política e econômica, o cansaço mental, o excesso de trabalho perturbando o convívio familiar, a incerteza, a falta de uma data para o término da pandemia, etc. Esses aspectos também são apontados por de Souza et al. (2020, p. 5) revelando que a "A ausência de um sistema de proteção e seguridade social proveniente do Estado e o enfraquecimento das redes de solidariedade em um cenário de incertezas e ameaças de desemprego parecem ter se aprofundado com a pandemia". Os excertos descritos a seguir revelam algumas destas angústias:

Medo de me contaminar quando encosto em algo na rua, medo de alguém da família se contaminar com o Covid, insegurança do futuro, sensação de impotência ao não poder escolher o que quero fazer, ao não poder sair de casa, medo de o meu filho entrar em depressão (P9).

Saudades de ver alguns familiares, amigos. Sinto falta da correria da faculdade, das aulas presenciais. Minha ansiedade agora que melhorou, mas no começo foi complicado (P10). 
Ansiedade em relação a saúde dos meus familiares, angustiada com a nossa situação política e, também com a situação de agressão constante e descaso com as mulheres (P12).

Preocupação com a segurança da saúde das minhas filhas, a dor das famílias vítimas do covid (P14).

Em como o ensino remoto afetará os estudantes em seu futuro. Preocupa-me a saúde mental em meio ao ensino remoto, pois há tantos professores e alunos relatando o cansaço físico e mental (P19).

Entre esta diversidade de angústias dois professores comentaram sobre o lado positivo da pandemia que está relacionado ao ficar mais em casa e como consequência, conviver mais com a família, dedicar mais tempo às formações de professores e ter mais tempo para si. Isso é visualizado nos excertos a seguir: "Tentando resumir em termos pessoais estou ativa, aproveitando o convívio familiar e o tempo para estar em casa. "Desculpa, mas tento ver aspectos positivos em tudo o que vivemos e fazemos. Estamos vivos, com saúde e emprego (eu, familiares e amigos mais próximos) o que já é muito positivo. Sente-se falta do presencial, do contato de estar com outros, sair (P26)." "No âmbito pessoal, apesar do distanciamento e dos cuidados, consigo ver alguns pontos positivos, como estar mais tempo com minha família, ter mais tempo para reflexão e conseguir realizar algumas formações”. (P27).

Como destaca o professor P27, a realização de formações continuadas durante o ano de 2020 pode ser um ponto positivo do momento vivido. Percebe-se que as universidades promoveram várias formações em parceria com a rede básica de ensino, exemplo disso, são as formações promovidas pela Universidade Federal do Pampa, Unipampa, durante os meses de abril a outubro de 2020, que organizou e implementou blocos de formações continuadas em parceria com os cursos de licenciatura dos 10 campi desta universidade, bem como em parceria com as secretarias municipais e as Coordenadorias do Estado do Rio Grande do Sul, CREs. Foram 58 formações, abrangeram vários Estados brasileiros (20 Estados) e contabilizaram 4259 inscrições.

A pandemia tem nos mostrado que as formações realizadas no modelo remoto têm um potencial para atingir um maior número de sujeitos participantes, bem como atingir professores de diferentes regiões do Brasil. Isso revela que o ensino remoto pode ser utilizado nas formações continuadas de professores, já que um dos desafios das formações é atingir com qualidade o maior número de sujeitos que consigam desenvolver esses 
percursos formativos, bem como, desenvolver ações de formação continuada por diversos setores do sistema público, assim como por organizações não governamentais, fundações, instituições ou consultorias privadas (GATTI, 2008).

\section{(2) Perspectivas do momento pós-pandemia.}

O momento vivenciado é na busca incansável da Ciência por uma vacina que poderá retardar o crescimento do coronavírus. Quando isto acontecer a sociedade viverá um novo normal, mas certamente as marcas desta pandemia serão relembradas e ficarão registradas na história mundial. Como sinalizam Barros Filho e Carmona (2020, p. 2):

Mas o vírus vai passar. E quando passar, será necessário não apenas reconstruir famílias que perderam seus entes e/ou que chafurdaram na miséria, mas sobretudo, voltar a trilhar um caminho da construção da prosperidade e do bem comum, no Brasil e no mundo.

Os autores Barros Filho e Carmona (2020) revelam a importância da reconstrução familiar, social e econômica, sendo necessária para que as pessoas voltem a ter um novo normal. Também sinalizam pelo menos 7 tendências neste mundo pós-pandêmico:

1. O surgimento de uma Era de incertezas quanto a quem será a potência que hegemonizará o sistema de Nações. Noutras palavras, veremos um período de aberta disputa pela liderança geopolítica entre as grandes potências. Isso já se ensaiava pelo menos desde a grande crise econômica de 2008, e no pós-Covid, se acentuará. Cabe uma lupa na chamada Nova Rota da Seda, em um investimento acima de trilhão de dólares em infraestrutura mundial, em rotas terrestres, polares e marítimas - aliás, parte do aço que a sustentará, trafegará na forma de minério de ferro de Carajás até os portos chineses; 2.A transição energética se acelerará. Ou seja, para uma economia de baixo carbono - o que exigirá ao Brasil acelerar a exploração de suas reservas de petróleo. Adicionalmente, a competição nos mercados globais de energia se intensificará: o mercado de energia global será o mais diversificado que o mundo já viu, com a disputa entre petróleo, gás, carvão e combustíveis não-fósseis. A demanda por gás natural já cresce fortemente e ultrapassou o carvão como a segunda maior fonte de energia. Energia solar e eólica serão de longe as fontes de energia que crescerão mais rapidamente; 3.A experiência global do Home Office obrigará a implantação acelerada da Internet $5 \mathrm{G}$; a disputa tecnológica por quem fornecerá a tecnologia " $5 \mathrm{G}$ " se intensificará, mas não haverá força material a deter sua implementação. Para atender à Internet 5T, o mercado global de satélites deve viver um movimento de aceleração. Principalmente com o lançamento de constelações de nano satélites (com pesos em torno de $1 \mathrm{Kg}$ ) - novamente, foco em Alcântara e no necessário relançamento do Programa Espacial Brasileiro; 4.O papel do 
Brasil como provedor de alimentos e proteína ao mundo se intensificará, assim como o protecionismo contra nossa condição de potência do agronegócio; 5.A pandemia mostrou que o sistema de saúde do planeta é sofrível. A tecnologia resolveu o problema da comunicação, mas o paradigma criado não mudou: o mundo deve se voltar para o Homem. Os sistemas de saúde públicos sairão fortalecidos. Se impõe a criação de sistemas de detecção e prevenção eficiente de novas pandemias - nisso, haverá um imperativo de cooperação entre as nações -, ao mesmo tempo em que se deve criar relativa autonomia no complexo industrial de Saúde, apoia da fortemente em investimentos em CT\&I em saúde; 6. Logo após a desaceleração forçada do mercado, os países investirão fortemente em infraestrutura e logística. A citada Rota da Seda é o maior exemplo; contudo, atenção para o papel especial que poderá ter o Eixo Central do Arco Norte do território nacional, nesse novo dinamismo que a infraestrutura poderá oferecer à economia nacional, que inclui a revolução logística que a finalização da Ferrovia Norte-Sul (FNS) e o sistema de Portos que ela alcançará já em 2021; 7.Por fim, haverá uma ruptura na tendência anterior de globalização econômica, em especial quanto às Cadeias Globais de Valor e de suprimentos. Sobretudo em insumos, bens e serviços estratégicos, isto é, dos quais não se pode depender do exterior em casos extremos, haverá que criar capacidade nacional (BARROS FILHO, CARMONA, 2020, p.3-4)

Diante deste cenário apresentado, a educação também passará por um novo normal, porém a maioria dos professores sujeitos desta pesquisa não discutiu questões políticas, econômicas e sociais ao serem perguntados sobre como será o momento póspandemia, mas apresentaram respostas relacionadas ao sentimento que cada um e cada uma está vivenciando. Isto ficou evidente nos excertos descritos a seguir:

De alegria, entusiasmo e muita vontade de seguir adiante (P2).

Um momento de adaptação para o convívio social coletivo (P5).

Acredito que todos não foi possível abraçar vamos fazer isso e aos poucos retomar a nossa rotina $(\mathrm{P} 7)$.

Diferente, com várias etapas da educação, por exemplo, on-line (P8).

Acredito que será complicado, pois será difícil a readaptação do ensino (P10).

Não tenho uma ideia formada, pois pelas imagens nas redes sociais, parece que as pessoas não aguentam mais ficar em isolamento, percebese muitas aglomerações sem cuidados básicos (P11).

Acredito que será importante rever os afetos, mas também será um momento de muito medo se a retomada a "normalidade" acontecer sem a presença da vacina (P12).

De muita expectativa que a vacina funcione e a vida volte à normalidade sem ter receio de contatos com outras pessoas (P16). 
Será muito bom, poder reencontrar várias pessoas, poder ir a faculdade...(P17).

Não penso que teremos um momento pós pandemia, pelo menos, não tão cedo. As pessoas, muitas delas, não enxergam ou fingem não entender o momento crítico que estamos vivendo. Vejo muitas pessoas levando a vida como se nada estivesse acontecendo (P19).

Triste, pois não retornaremos igual entramos. Mas ao mesmo tempo loucos por contatos além dos virtuais (P22).

Muito difícil, acho que é uma situação traumatizante, estaremos em um pós trauma muito complicado (P23).

Se as atividades remotas se somarem a atividades presenciais, como estamos vendo com alguns casos, será impossível se manter bem e dar conta de tudo. Sinceramente, tenho receio e quero aprender a lidar com isso, dizendo nãos necessários. Só que vejo que os convites são porque os colegas também estão assoberbados...pedem auxílio. Então quero me unir aos colegas, mas quero estar bem para isso. Vamos pensar e fazer juntos um modo de trabalhar, pós-pandemia. Não aceitando o imposto, mas propondo o que pensarmos juntos (P24).

Correr atrás do tempo perdido, reinvenção muita luta força foco e muita fé (P25).

Não tenho ideia, busco não pensar muito sobre o lá na frente, pois não temos a certeza de que vai passar rápido. Para tentar aliviar a ansiedade, tento pensar no agora (P28).

A maior parte das respostas está relacionada à falta do convívio social e o receio em enfrentar este novo normal. Poucos professores relacionaram as suas respostas com questões sobre políticas públicas da educação, economia, acesso ao uso das tecnologias, vulnerabilidade social, etc. Isso é visualizado nos excertos a seguir:

Não tenho muita esperança. O vírus está deixando ainda mais explícitas as mazelas e anormalidades do modo capitalista de funcionar o mundo. Minha ideia, e é claro eu não gostaria que assim fosse, é que para a educação pública será ainda pior. Para o público, será tudo pior! Uma pena! Mas continuarei no movimento de contracorrente de poder fazer algo em direção juntamente ao contrário na educação que é sim, uma questão pública como venho repetindo faz tempo (P4).

[...] Em relação ao trabalho, penso que teremos diversas alterações nas estruturas de cursos, eventos, aulas (o ensino virtual vai permanecer em boa parte), o ensino híbrido poderá ser uma alternativa viável, mas espero que sejam resolvidos os problemas de acesso à internet, que seja acessível para todos incluindo os computadores, celulares.... Também 
espero que o momento pós-pandemia seja de reflexão, de cautela, mas no fundo, penso que será caótico, com desemprego, retorno da inflação, fome, miséria, violência, um caos (P13).

Caos econômico, pessoas mais humanas, educação em crise (P18)

Na verdade, evito pensar. Sei que ficarão muitas lacunas nos processos de ensino e aprendizagem e infelizmente muitos irão preferir mascarar a realidade, como já o fazem, ao invés de criar alternativas para minimizá-las. Tento não ser pessimista e buscar os lados positivos do momento que vivenciamos, mas em termos de educação vejo um cenário ainda mais deficiente e ineficaz do que já se encontrava (P27).

\section{Considerações finais}

As perspectivas dos professores pós-pandemia se referem, em sua maioria, a questões de convívio social, há inexistência de discussões sobre as políticas públicas que poderiam ser adotadas no momento pós-pandemia parece ser consenso entre as respostas dos professores. Há apenas alguns professores que discutem questões de direito à educação pública, e alguns apontamentos levantados sobre a modalidade de ensino híbrido, o acesso à interne e o agravamento da situação econômica no país.

Percebi que são muitas aflições sinalizadas pelos docentes, mas também há aqueles que conseguem vislumbrar deste momento pontos positivos, principalmente sobre estar mais entre os familiares e por dispor de um tempo maior para fazer as formações, evitando os deslocamentos, já que as formações estão ocorrendo de forma remota. Isso revela que os professores estão vivenciando um momento de exaustão pessoal, pois o que reflete nas falas são questões menos politizadas e mais introspectivas.

Espero ter revelado nestas cartas o momento que estamos passando. São momentos difíceis e dolorosos, pois além das questões de angústias e perspectivas do momento pós-pandemia, presenciamos um cenário de precariedade da educação.

No sentido de contribuir na formação docente e seguir na contramão da precariedade do ensino público devemos apostar nos espaços coletivos de formação e o Cirandar é um desses espaços que acolhe e escuta o professor.

\section{REFERÊNCIAS}


BARROS FILHO, Allan Kardec Duailibe; CARMONA, Ronaldo Gomes. O MUNDO PÓS-COVID: RUPTURAS E CONTINUIDADES. NOTAS PROSPECTIVAS. Ciências Jurídicas e Sociais-IURJ, v. 1, n. 1, p. 195-198, 2020.

BRASIL. Decreto n. ${ }^{\circ}$ 7616. Dispõe sobre a declaração de Emergência em Saúde Pública de Importância Nacional - ESPIN e institui a Força Nacional do Sistema Único de Saúde - FN-SUS. Lex: Coletânea de Legislação e Jurisprudência, Distrito Federal, 2011. Disponível em: Acesso em: 12 dez. 2020.

CORREIO BRAZILIENSE. Brasília: Diários Associados (DA), [2021]-. Diário. Disponível em: https://www.correiobraziliense.com.br/ultimas-noticias/ Acesso em 04 de janeiro de 2021 às $16 h$.

CUI J.; LI F.; SHI Z. L. Origin and evolution of pathogenic coronaviruses. Nature Reviews. Microbiology Reviews, v.17, n.3, p.181-192, 2019.

DE SOUZA, K. R. et al. Trabalho remoto, saúde docente e greve virtual em cenário de pandemia. Trabalho, Educação e Saúde, v. 19, 2021.

FIORI, R; GOI, M. E. J. O Ensino de Química na plataforma digital em tempos de Coronavírus. Revista Thema, v. 18, p. 218-242, 2020.

GATTI, B. A. Análise das políticas públicas para formação continuada no Brasil, na última década. Revista Brasileira de educação, v. 13, n. 37, p. 57-70, 2008.

MINAYO, M. C. S.; SANCHES, O. Quantitativo-Qualitativo: oposição ou complementaridade? Cad. Saúde Pública, v.9, n.3, p. 239-262, 1993.

WANG, Y.; SHANG, J.; GRAHAM, R.; BARIC, R. S. et al. Receptor recognition by the novel coronavirus from Wuhan: an analysis based on decade-long structural studies of SARS Coronavirus. Journal of Virology, v.94, n.7, p.e00127-20(1-9), dez. 2020. 